\title{
On the road to diploidization? Homoeolog loss in independently formed populations of the allopolyploid Tragopogon miscellus
} (Asteraceae)

\author{
Jennifer A Tate*1, Prashant Joshi ${ }^{1}$, Kerry A Soltis ${ }^{2}$, Pamela S Soltis ${ }^{3,4}$ and \\ Douglas E Soltis ${ }^{2,4}$
}

Address: ${ }^{1}$ Institute of Molecular BioSciences, Massey University, Palmerston North, New Zealand, ${ }^{2}$ Department of Biology, University of Florida, Gainesville, Florida, USA, ${ }^{3}$ Florida Museum of Natural History, University of Florida, Gainesville, Florida, USA and ${ }^{4}$ Genetics Institute, University of Florida, Gainesville, Florida, USA

Email: Jennifer A Tate* - j.tate@massey.ac.nz; Prashant Joshi - p.joshi@massey.ac.nz; Kerry A Soltis - kerry1@ufl.edu;

Pamela S Soltis - psoltis@flmnh.ufl.edu; Douglas E Soltis - dsoltis@botany.ufl.edu

* Corresponding author

Published: 27 June 2009

BMC Plant Biology 2009, 9:80 doi:10.1 I86/147|-2229-9-80
Received: 5 May 2009

Accepted: 27 June 2009

This article is available from: http://www.biomedcentral.com/I47I-2229/9/80

(C) 2009 Tate et al; licensee BioMed Central Ltd.

This is an Open Access article distributed under the terms of the Creative Commons Attribution License (http://creativecommons.org/licenses/by/2.0), which permits unrestricted use, distribution, and reproduction in any medium, provided the original work is properly cited.

\begin{abstract}
Background: Polyploidy (whole-genome duplication) is an important speciation mechanism, particularly in plants. Gene loss, silencing, and the formation of novel gene complexes are some of the consequences that the new polyploid genome may experience. Despite the recurrent nature of polyploidy, little is known about the genomic outcome of independent polyploidization events. Here, we analyze the fate of genes duplicated by polyploidy (homoeologs) in multiple individuals from ten natural populations of Tragopogon miscellus (Asteraceae), all of which formed independently from $T$. dubius and $T$. pratensis less than 80 years ago.

Results: Of the 13 loci analyzed in 84 T. miscellus individuals, I I showed loss of at least one parental homoeolog in the young allopolyploids. Two loci were retained in duplicate for all polyploid individuals included in this study. Nearly half (48\%) of the individuals examined lost a homoeolog of at least one locus, with several individuals showing loss at more than one locus. Patterns of loss were stochastic among individuals from the independently formed populations, except that the $T$. dubius copy was lost twice as often as $T$. pratensis.

Conclusion: This study represents the most extensive survey of the fate of genes duplicated by allopolyploidy in individuals from natural populations. Our results indicate that the road to genome downsizing and ultimate genetic diploidization may occur quickly through homoeolog loss, but with some genes consistently maintained as duplicates. Other genes consistently show evidence of homoeolog loss, suggesting repetitive aspects to polyploid genome evolution.
\end{abstract}

\section{Background}

Allopolyploidy combines the processes of hybridization with genome doubling, and together, these provide a potential avenue for instantaneous speciation [1-3].
Whole-genome sequencing efforts have revolutionized our thinking about the significance of polyploidy, as it is clear that paleopolyploidy is a common phenomenon. Ancient whole-genome duplications have been detected 
in many eukaryotic lineages, including angiosperms, vertebrates, and yeast [4-12]. Polyploidy has been particularly prevalent in flowering plants, where previous estimates indicated that $30-70 \%$ of angiosperm species had polyploidy in their ancestry [reviewed in [13]]. In the last decade, the view of polyploidy in angiosperms has changed, and it is now appreciated that perhaps all angiosperm lineages have experienced at least one round of polyploidy, with many lineages undergoing two or more such episodes [14-18]. On more recent timescales, molecular data have also revealed that most extant polyploid plant species have formed recurrently [1,19-28]. In fact, very few examples of a single unambiguous origin of a polyploid species have been documented; these include peanut, Arachis hypogaea, the salt marsh grass Spartina anglica, and Arabidopsis suecica [29-32].

Following allopolyploidization, several evolutionary outcomes are possible for the genes duplicated by polyploidy (homoeologs). Both copies may be retained in the polyploid and remain functional, one copy may accumulate mutations and either diverge in function or become silenced, or one copy may be physically lost $[8,33,34]$. The fate of these duplicated gene pairs seems to vary depending on the system under investigation and the loci involved [35-41]. Over longer evolutionary timeframes, gene loss, genome downsizing, and, ultimately, genetic 'diploidization' appear to be common phenomena $[8,42$ 45]. Homoeologous recombination appears to play an important role in the loss of small genomic fragments during the early stages of polyploid formation [46-50], which contributes to gene loss and genome downsizing in allopolyploids [39,43,51,52]. Wolfe (2001) pointed out that within a species, some loci may remain 'tetraploid', while others are diploidized; evidence from wholegenome analyses supports this idea [e.g., [36,40]]. Although polyploidy is clearly a recurrent process on both recent and ancient timescales, we know very little about the evolutionary fate of genes duplicated by polyploidy in independently formed allopolyploid populations. Specifically, are homoeologs consistently retained or lost in a repeated manner among individuals from independently formed polyploid populations?

The allopolyploids Tragopogon mirus and T. miscellus (Asteraceae) are textbook examples of speciation following polyploidy and provide an ideal system to investigate the evolutionary fate of duplicated genes in independently formed populations. These allopolyploids formed recently in the Palouse region of the western United States (eastern Washington and adjacent Idaho) following the introduction of three diploid species (T. dubius, T. porrifolius, and T. pratensis) from Europe in the early 1900s [53]. Tragopogon mirus formed independently several times from T. dubius and T. porrifolius, while T. miscellus formed multiple times from $T$. dubius and T. pratensis [53-57]. Only T. miscellus has formed reciprocally in nature, and these reciprocally formed individuals can be distinguished morphologically. The 'short-liguled' form has $T$. pratensis as the maternal progenitor, while the 'longliguled' form has $T$. dubius as the maternal parent (Figure 1). Today, only one long-liguled population exists (in

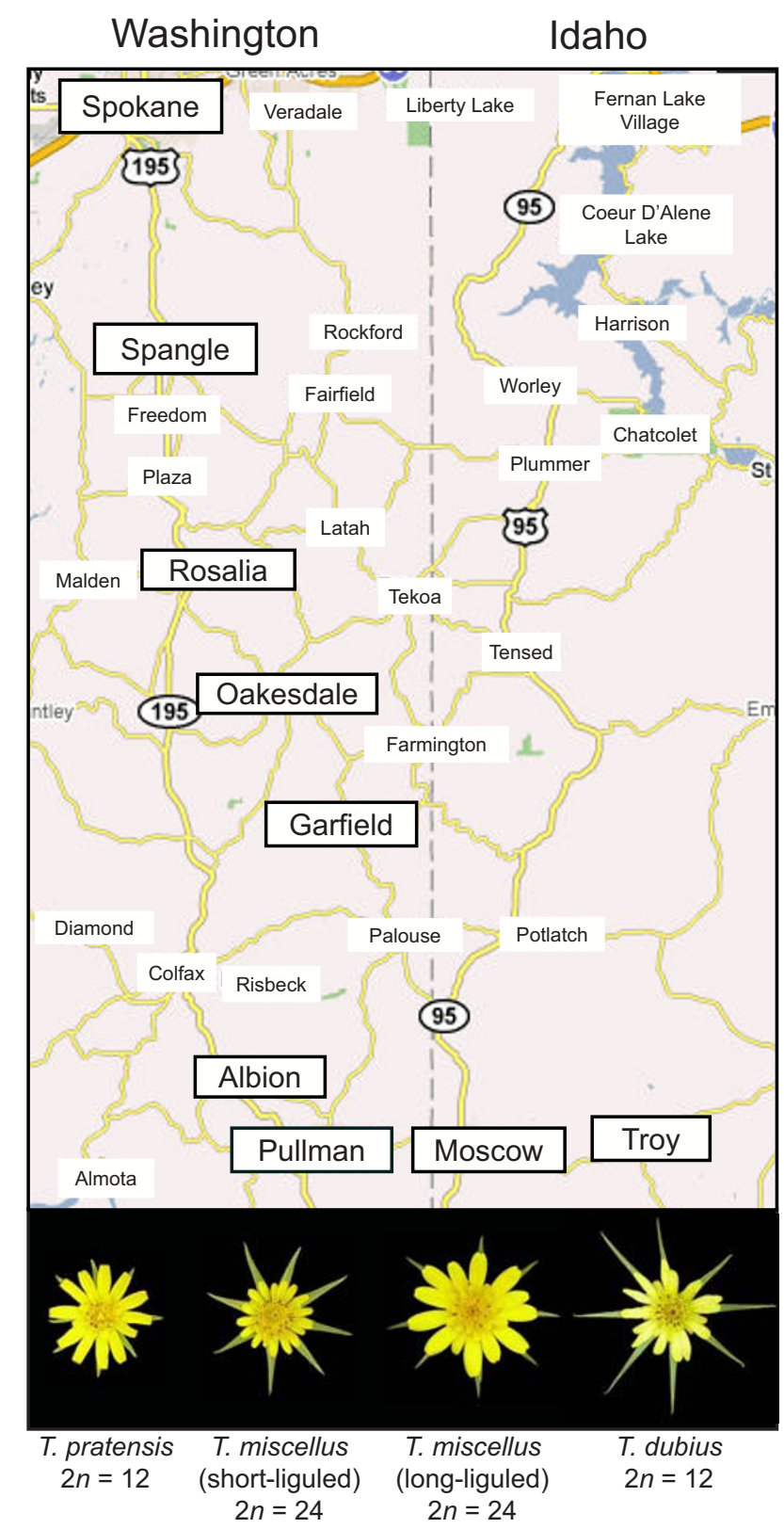

\section{Figure I}

Tragopogon populations sampled. Populations of Tragopogon sampled (boxed) in the United States and representative capitula of the diploid (T. dubius and T. pratensis) and allotetraploid (T. miscellus) species. Map modified from Google Maps. 
Pullman, Washington; Figure 1); all other populations of T. miscellus are short-liguled [58]. Molecular data have confirmed that the populations of T. mirus and T. miscellus in the Palouse have arisen independently (reviewed in Soltis et al. 2004; Symonds et al. in prep.).

In this study, we examine ten populations of T. miscellus for 13 loci to investigate the fate of homoeologous loci in natural populations of Tragopogon miscellus. Our previous study [59] revealed that T. miscellus individuals from two populations (one each of short- and long-liguled forms) had experienced loss of one parental homoeolog for seven of ten loci examined. This loss was not fixed within or between populations, nor was homoeolog loss 'fixed' for any particular locus examined. Three of these loci were retained in duplicate for all individuals examined. Another recent study has also demonstrated loss of homoeologous loci for five T. miscellus populations for a different set of ten genes [60]. In addition to loss, homoeolog silencing has also occurred in these recent allopolyploids $[59,60]$. Because multiple origins typify most allopolyploid species [27], we extended these previous studies of $T$. miscellus to examine the extent to which parental homoeologs might be lost from individuals from several natural populations and to assess if recurrent patterns of homoeolog loss or retention could be detected in these independently formed populations.

\section{Results}

\section{Genomic CAPS analyses}

Two hundred individuals (83 T. dubius, $33 \mathrm{~T}$. pratensis, and $84 \mathrm{~T}$. miscellus) from 10 populations (Table 1) were screened for 13 markers Table 2). Variation in the restriction digestion patterns of Tragopogon dubius was evident for a single marker (TDF72.3) (Figure 2). No variation was observed in $T$. pratensis based on the present sampling. Two individuals, each grown from a seed collected from a T. dubius plant in the field (one each from Troy and Albion), apparently were hybrids, as the individuals possessed both $T$. pratensis and T. dubius fragment patterns in the genomic restriction digests for all markers screened (data not shown). Because T. pratensis does not occur in either locality, these individuals likely represent hybrids between T. miscellus and T. dubius.

Combining the new data generated here with data from Tate et al. (2006), for the 13 loci examined, 11 showed loss of a homoeolog in at least one of the T. miscellus

Table I: Populations of Tragopogon analyzed. Populations are ordered geographically from north to south.

\begin{tabular}{|c|c|c|c|}
\hline Population & Species & Population ID* & Number of individuals \\
\hline \multirow[t]{4}{*}{ Spokane, WA } & T. pratensis & -- & -- \\
\hline & T. miscellus & 2664 & 7 \\
\hline & T. miscellus & 2617 & 8 \\
\hline & T. dubius & 2665 & 7 \\
\hline \multirow[t]{3}{*}{ Spangle, WA } & T. pratensis & 2692 & 9 \\
\hline & T. miscellus & 2693 & 10 \\
\hline & T. dubius & 2616 & 10 \\
\hline \multirow[t]{3}{*}{ Rosalia, WA } & T. pratensis & -- & -- \\
\hline & T. miscellus & 2667 & 2 \\
\hline & T. dubius & 2666 & II \\
\hline \multirow[t]{3}{*}{ Oakesdale, WA } & T. pratensis & 2672 & 10 \\
\hline & T. miscellus & 2671 & 10 \\
\hline & T. dubius & 2670 & 9 \\
\hline \multirow[t]{3}{*}{ Garfield, WA } & T. pratensis & 2689 & 4 \\
\hline & T. miscellus & 2688 & 10 \\
\hline & T. dubius & 2687 & 7 \\
\hline \multirow[t]{3}{*}{ Albion, WA } & T. pratensis & -- & -- \\
\hline & T. miscellus & 2625 & 8 \\
\hline & T. dubius & 2691 & 10 \\
\hline \multirow[t]{3}{*}{ Pullman, WA** } & T. pratensis & - & -- \\
\hline & T. miscellus & 2605 & 10 \\
\hline & T. dubius & 2613 & 10 \\
\hline \multirow[t]{3}{*}{ Moscow, ID } & T. pratensis & 2608 & 10 \\
\hline & T. miscellus & 2604 & 10 \\
\hline & T. dubius & -- & -- \\
\hline \multirow[t]{4}{*}{ Troy, ID } & T. pratensis & -- & -- \\
\hline & T. miscellus & 2682 & 9 \\
\hline & T. dubius & 2683 & 14 \\
\hline & T. dubius & 2686 & 5 \\
\hline
\end{tabular}

* Soltis and Soltis collection numbers; **long-liguled population 
Table 2: Loci analyzed.

\begin{tabular}{lcc}
\hline Locus ID & Gene abbreviation & Putative protein/gene \\
\hline TDF7 & CKINS & Casein kinase \\
TDFI7.4 & UBQ & Polyubiquitin \\
TDF36.3 & THIOR & Thioredoxin M-type I \\
TDF44 & LTR2 & Leucine-rich repeat transmembrane protein kinase \\
TDF46 & PP2C & Protein phosphatase 2C family protein \\
TDF62 & AUX & Auxin conjugate hydrolase \\
TDF72.3 & ADG & Putative adenine-DNA glycosylase \\
TDF74 & TDRC & Transducin family protein \\
TDF85 & BFRCT & B-fructosidase \\
TDF90 & GTPB & Small GTP-binding protein \\
TDF27.10 & PSBO & Oxygen-evolving enhancer \\
cryl & cryl & Cryptochrome I \\
nrDNA & nrDNA & Nuclear ribosomal DNA \\
\hline
\end{tabular}

individuals surveyed (See Additional file 1; Figure 2). For two genes (TDF46 and TDF85), both parental homoeologs were retained in all individuals examined. Some genes showed loss more frequently than others. For example, a T. pratensis homoeolog of TDF17.4 was lost in only one individual, while for TDF90, 18 individuals lost either the T. dubius or T. pratensis copy. For the genes that showed losses, 20 losses were from the $\mathrm{T}$. pratensis genome, while 40 were from the $\mathrm{T}$. dubius genome $\left(\chi^{2}=\right.$ 6.667, $\mathrm{df}=1, \mathrm{P}<0.001)$. Considering the genic patterns across populations, none of the genes showed loss in every population. One gene, TDF36.3, showed loss in at least one individual from all but one population (Troy).

Forty of the $84 \mathrm{~T}$. miscellus individuals surveyed showed loss of a homoeolog for at least one locus, with 15 of these showing loss for multiple loci (See Additional file 1). For example, individual 2693-14 from Spangle lost the $T$. dubius homoeolog for both TDF7 and TDF90 and lost the T. pratensis homoeolog for TDF62; individual 2625-3 from Albion lost the T. pratensis copy for TDF7, TDF44, TDF74, TDF36.3, TDF27.10, and $c r y 1$. For individuals that

\section{Oakesdale}

A TDF85

B TDF72.3
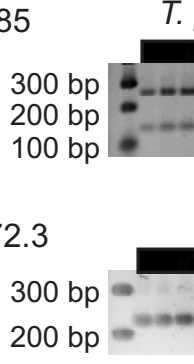

T. pratensis
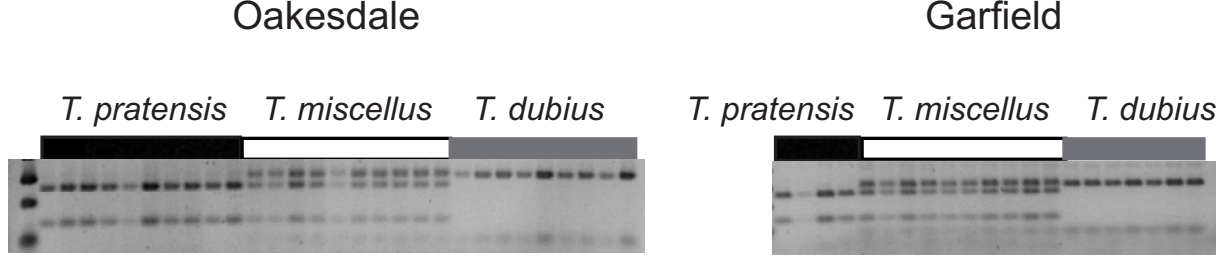

Garfield

$$
\begin{aligned}
& 300 \text { bp } \\
& 200 \text { bp }
\end{aligned}
$$ \\ $300 \mathrm{bp}$
$200 \mathrm{bp}$}

C $\quad \operatorname{cry} 1$

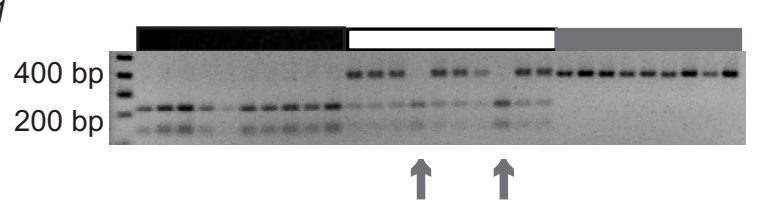

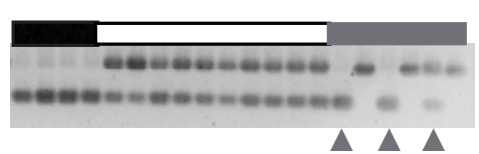

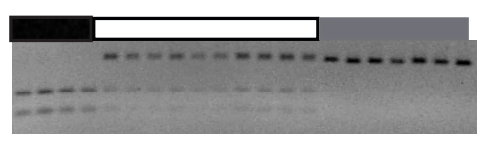

Figure 2

Loss and retention of homoeologous loci in Tragopogon miscellus. Representative genomic CAPS results for three loci from two populations of Tragopogon miscellus. An arrow indicates a loss, and an arrowhead indicates allelic variation. A. TDF85 showed no losses in any of the populations examined. B. Allelic variation was present in T. dubius from Garfield for TDF72.3. A 'missing' fragment in T. miscellus from Oakesdale may be interpreted as a loss, or the pattern may result from the polyploid individual arising from a $T$. dubius individual with an allele that is similar in its digest pattern to T. pratensis. C. cryl showed loss in some individuals and some populations, but not others. 
lost a homoeolog at more than one locus, the same parental homoeolog was lost more often than different homoeologs (i.e., 11 individuals lost homoeologs from the same parent, while four individuals lost alternative homoeologs). Of those that lost the same parental homoeolog, nine cases were losses of $T$. dubius, while two were losses of $T$. pratensis. Considering all populations, regardless of the parental origin, the loss of one homoeolog was the most common scenario ( 25 cases), followed by homoeolog losses at two loci in eight individuals, three loci in six individuals, and six losses in one plant (individual 26253 from Albion, mentioned above). For these multiple losses, no clear pattern emerged (i.e., when two or more loci were lost from multiple individuals, they were not the same pairs of loci).

At the population level, differences in the number of losses were also evident, but without a clear genomic, genic, or geographical pattern (See Additional file 1). The Albion and Moscow populations showed the greatest number of total homoeolog losses (12 losses in three and seven individuals, respectively), followed by Oakesdale (nine losses in five individuals), Pullman (eight losses in six individuals), Spokane-2617 (six losses in five individuals), Garfield (six losses in five individuals), Spangle (six losses in four individuals), Troy (four losses in two individuals), Rosalia (one), and Spokane-2664 (one). The number of individuals (within a population) that showed the same pattern of loss varied by population. The Spokane-2664, Spangle, Rosalia, Garfield, Moscow, and Troy populations did not have any individuals that shared patterns of loss. Spokane-2617 and Pullman each had three individuals with shared patterns, while Oakesdale and Albion each had two individuals. Shared losses among individuals within a population may represent inheritance of a loss that occurred in a common ancestor.

\section{Discussion}

\section{Homoeolog loss in independently formed populations}

Our extended survey of 13 loci for ten populations of Tragopogon miscellus indicates that some genes are maintained in duplicate in all populations, while others show loss among some individuals from the independently formed populations. This result is consistent with our previous finding of loss in two populations (Moscow and Pullman) for ten of these same genes [59]. Although homoeolog loss is not unique to Tragopogon, the present study represents the largest survey of individuals from natural populations conducted thus far. Homoeolog loss appears to be a common phenomenon in polyploids and may occur rapidly following their formation. For example, synthetic polyploids of wheat [47] and Brassica $[46,48,61]$ show loss of homoeologous loci in early generations. In Tragopogon, we have not detected loss in $\mathrm{F}_{1}$ hybrids or first-generation synthetic polyploids $[59,60]$.
Thus, homoeologous loss does not appear to occur instantaneously upon hybridization or polyploidization in Tragopogon, at least based on the loci examined thus far.

Given that genome downsizing and other processes may ultimately contribute to genetic 'diploidization' in polyploid organisms $[8,43]$, what impact does homoeolog loss have on recently and independently formed polyploid populations? Our data indicate that homoeolog loss in Tragopogon miscellus is stochastic among individuals from polyploid populations that are less than 80 years old ( $<40$ generations as these are biennials). Almost half $(48 \%)$ of the individuals surveyed here showed loss of a homoeolog for at least one locus, with some populations showing loss more frequently than others. Five of these same populations were examined for a different suite of ten genes by Buggs et al. (2009), and a similar result was found. The Moscow population showed the greatest number of losses (eight), followed by Oakesdale (five), Garfield (three), Spangle (one), and Pullman (one). Some of the same individuals were examined here and as part of that study, but again, no clear pattern of loss among individuals and populations could be identified. Given the ecological success of T. miscellus, which is widespread in the Palouse and whose range is expanding [58], this loss does not appear to negatively affect the individuals or populations. When Ownbey [53] first described T. miscellus and T. mirus, he found that fertility (seed set) averaged $52-66 \%$ in the natural populations, but with a great deal of variation outside this range among individuals. More recent surveys of the natural populations indicate that fertility (based on pollen stainability) is high, averaging 95$100 \%$ (P. Soltis and D. Soltis, unpublished data), which suggests that following their initial formation the polyploid individuals experience some genomic instability, but eventually become more stabilized. Recently, we resynthesized allopolyploids of both $T$. miscellus and $T$. mirus [62]. The initial $S_{1}$ plants exhibited slightly reduced pollen stainability and fruit set; but successful lineages that have survived to the $S_{2}$ generation exhibit high fertility. Through homoeolog loss, perhaps the polyploid individuals from natural populations are still sorting out potential genomic incompatibilities resulting from hybridization and genome doubling [63]. It will be important to follow the synthetic polyploids through successive generations to determine when homoeolog loss occurs and if this loss contributes to increased fertility.

One consistent pattern among the populations that has emerged from the present study is that $T$. dubius homoeologs appear to be lost more often than those of $T$. pratensis, particularly when two or more loci undergo loss, and this difference in losses is statistically significantly different $(P<0.001)$ (See Additional file 1$)$. Combining the data presented here with those from Tate et al. (2006), we 
find that loss of a T. dubius homoeolog represents $67 \%$ of the total losses, while loss of the T. pratensis copy represents $33 \%$ of the total losses. Why the T. dubius copy is eliminated more frequently is not known. Significantly, other allopolyploids, including wheat $[49,64]$ and Brassica [61], also show biased elimination of one parental genome over the other. The loss of T. dubius homoeologs is especially evident for nrDNA (See Additional file 1 , Figure 3 ) and is consistent with previous studies of nrDNA evolution in natural populations of $T$. mirus and T. miscellus $[65,66]$. Matyášek et al. (2007) found that although the allopolyploids had fewer T. dubius nrDNA copies, these were preferentially expressed over the alternative parental copies (i.e., either T. porrifolius or T. pratensis for T. mirus and T. miscellus, respectively). In the present study, we also identified a few individuals that have reduced $T$. pratensis nrDNA copy numbers relative to $T$. dubius. These individuals were from both short- and longliguled T. miscellus populations (See Additional file 1, Figure 3). This bi-directional concerted evolution of nrDNA copies has also been demonstrated in more ancient allopolyploids, such as Gossypium (G. tomentosum, G. hirsutum, G. darwinii, G. barbadense, and G. mustelinum) [67].

The loss or retention of certain classes of genes appears to be a recurrent pattern when ancient whole-genome duplication patterns are examined, although the classes that are retained in duplicate differ depending on the lineage under study $[35,36,41,68]$. For example, in Asteraceae, Barker $e t$ al. (2008) found that genes associated with structural components and cellular organization were retained in duplicate, while genes involved with regulatory (e.g., transcription factors) and developmental functions lack duplicates. In Arabidopsis (Brassicaceae) and rice (Poaceae), however, genes involved with transcription were retained in duplicate [36]. In Tragopogon miscellus, the two genes that were retained in duplicate (TDF46 and TDF85) in all individuals did not fall into the category of significantly enriched (or reduced) when compared to the Barker et al. (2008) study. Similarly, the genes that were lost did not match gene ontology (GO) slim categories that were significantly either underrepresented or enriched. TDF46 is a putative protein phosphatase 2C family protein that functions in the plasma membrane, and TDF85 is a putative $\beta$-fructosidase that acts in the vacuole. As additional genomic resources are developed for Tragopogon and these genes are analyzed in the polyploid species, it will be imperative to determine whether certain gene classes are consistently lost or retained following allopolyploidization.

\section{Mechanism for homoeolog loss}

Studies of Brassica [46,50,61] allopolyploids have revealed a significant role for homoeologous recombination in DNA loss, although this process does not appear to affect wheat allopolyploids [38]. A recent karyological study using fluorescent and genomic in situ hybridization (FISH, GISH) of natural and synthetic Tragopogon allopolyploids identified extensive chromosomal changes, including monosomy and trisomy, intergenomic translocations, and variation in nrDNA loci [69]. Importantly, the same study [69] showed that some chromosomal changes occurred in the first synthetic generation of $T$. mirus (synthetics of $T$. miscellus have not yet been investigated). Ownbey [53] observed multivalent formation in individuals of T. mirus and T. miscellus from natural populations and also noted univalents and a ring of four chromosomes in $\mathrm{F}_{1}$ hybrids between $T$. dubius and T. pratensis. We have also observed frequent multivalent formation in synthetic lineages of $T$. mirus and T. miscellus [62]. These prevalent meiotic irregularities suggest a mechanism for the homoeolog losses observed here. That is, through homoeologous recombination in early generations following polyploid formation, genome reshuffling and gene loss could act to stabilize the new polyploid genome [63]. Perhaps in Tragopogon a combination of factors acts over time to stabilize the new polyploid genomes. For example, some chromosomal changes could happen immediately following polyploid formation, with homoeolog loss acting gradually over successive generations. The study of additional genes and comparisons with synthetic T. miscellus lineages [62] over several generations will be important for establishing the overall pattern of genome change in this system.

\section{Conclusion}

Our survey of 13 homoeologous loci in individuals from ten populations of Tragopogon miscellus represents the most extensive survey of the fate of duplicate genes in allopolyploid genomes from independently formed natural populations. In this species, loss of a parental homoeolog has occurred for several loci in individuals from these populations. Some loci are consistently maintained as duplicates in all individuals from these populations. Other genes consistently show evidence of homoeolog loss across populations of independent origin; significantly, the T. dubius homoeolog is typically lost. Hence, some aspects of genome evolution appear to have been repeated in these new polyploids. In these young ( 40 generations) allopolyploids, genomic incompatibilities may be resolved, in part, through loss of a parental homoeolog for some loci. As polyploidy and genome downsizing are recurrent processes in many lineages, other polyploid groups should be investigated to determine if similar patterns emerge for the loss and retention of genes duplicated by polyploidy. 

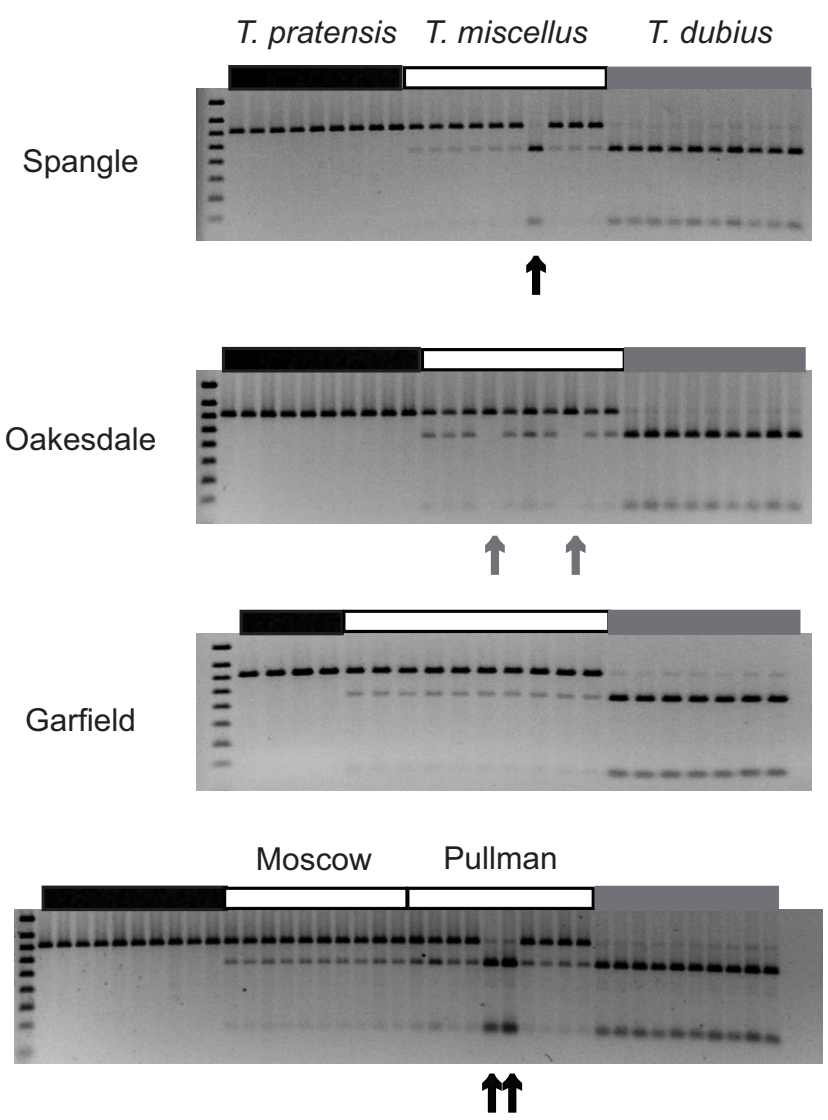

Figure 3

nrDNA variation in populations of Tragopogon miscellus. Most individuals show genomic digest profiles of $T$. pratensis nrDNA copies $>T$. dubius nrDNA copies, although a few individuals show the opposite pattern, and some individuals have lost a parental locus entirely (indicated by an arrow).

\section{Methods}

\section{Plant material and population sampling}

Mature fruiting heads of Tragopogon dubius, T. miscellus, and $T$. pratensis were collected from multiple individuals from several populations in Washington and Idaho, USA, in July 2005 (Table 1). Seeds were germinated in $11.4 \mathrm{~cm}$ pots in a glasshouse at the University of Florida (Gainesville, FL, USA) under standard conditions. Material from Pullman, Washington, and Moscow, Idaho, was utilized from a previous study [59].

In total, we included ten populations of T. miscellus, four populations of $T$. pratensis, and nine populations of $T$. dubius (Table 1). Our sampling strategy was intended to survey as many individuals and populations from the Palouse as possible. Similarly, we recognize that sympatric diploid populations may not represent the progenitor genotypes for a particular local polyploid population (although they typically do; Symonds et al. unpublished). Therefore, we wanted to survey as many diploid individuals as possible to screen for potential variation in the loci examined. The number of populations and number of individuals from the diploid populations included in the study differed because of changes in population dynamics since the formation of the Tragopogon polyploids [70]. For example, while once locally common, $T$. pratensis has become sparse in the Palouse over the last several decades [58] and is not always found in the vicinity of T. miscellus populations (Table 1). Nevertheless, data accumulated from previous studies [23,57] indicate that very little genetic variation exists within and between populations of T. pratensis in the Palouse. On the other hand, T. dubius is more widely distributed [58] and harbors more genetic variation than does T. pratensis [57]. Of the two diploid parents of T. miscellus, $T$. dubius is more likely to exhibit variation in the genes examined.

\section{Genomic CAPS analysis}

To determine if parental homoeologs were maintained or lost in the Tragopogon miscellus individuals from independently formed populations, we used genomic cleaved amplified polymorphic sequence (CAPS) analysis [71]. Leaf material was harvested from seedlings and DNA extracted following a modified CTAB protocol [72]. For two of the three loci not previously analyzed (cry1 and TDF27.10), primers were designed from Tragopogon dubius sequences using Primer3 [73]. The cry1 sequence originated from an EST library of $T$. dubius (Tdu016MS1_D11.e), and the TDF27.10 (TDF stands for transcript-derived fragment) sequence was derived from a previous CDNA-AFLP study [59]. Primer sequences for these two loci were cry1-1F: 5'-AATGGTTCCCAGTTTGACCA-3', cry1-1R: 5-GGCAAAGTTTTACCCGGTTT-3'; TDF27.10F: 5'-CATTCATGCAACCAACCAAG-3', TDF27.10R: 5'CTTCGGACTTCCTTCAGCAC-3'. These primers were used to amplify genomic DNA from T. dubius and T. pratensis with the aim of identifying sequence polymorphisms that could distinguish the homoeologs in T. miscellus. Genomic amplifications were conducted in a $25 \mu \mathrm{L}$ volume with 50 ng template, 10× Thermopol buffer (New England Biolabs, Ipswich, MA, USA), $0.4 \mathrm{mM}$ dNTPs, 0.2 $\mu \mathrm{M}$ each primer, and 0.5 unit Taq polymerase (New England Biolabs). Thermal cycling conditions were as follows: $94^{\circ} \mathrm{C}$ for $2 \mathrm{~min}$, followed by 35 cycles of $94^{\circ} \mathrm{C}$ for $30 \mathrm{sec}$, $52-54^{\circ} \mathrm{C}$ for $30 \mathrm{sec}, 72^{\circ} \mathrm{C}$ for $1 \mathrm{~min}$, and a final 5-min extension at $72^{\circ} \mathrm{C}$. Products were separated on a $1.5 \%$ agarose gel, stained with ethidium bromide, and visualized by UV on a transilluminator. PCR products were prepared for sequencing by adding 5 units of Exonuclease I (Fermentas, Glen Burnie, MD, USA) and 0.5 unit Shrimp alkaline phosphatase (Fermentas) and treating them at $37^{\circ} \mathrm{C}$ for $30 \mathrm{~min}$ followed by $80^{\circ} \mathrm{C}$ for $15 \mathrm{~min}$. Cleaned products were separated on an $\mathrm{ABI} 3770$ following the 
manufacturer's recommendation (Applied Biosystems, Foster City, CA, USA). Sequences were edited in Sequencher version 4.7 (Gene Codes, Ann Arbor, MI, USA) and deposited in GenBank under accession numbers FJ770374-FJ770377. To determine if sequence polymorphisms between the two diploid parental sequences occurred at a restriction site, the sequences were analyzed with dCAPS Finder 2.0 [74]. For cry1, the restriction enzyme Acil cut the T. pratensis 382-bp product into two fragments (232 and $150 \mathrm{bp}$ ), while the $T$. dubius product remained uncut (385 bp). For TDF27.10, MseI cut the T. pratensis PCR product into two fragments $(216$ and 83 bp), and the T. dubius product remained uncut at $299 \mathrm{bp}$. Restriction digestions for both markers were conducted in a 10- $\mu$ l volume with $1 \times$ buffer (New England Biolabs), 1 $\mu \mathrm{L}$ PCR product, 5-10 units of enzyme (New England Biolabs), and $100 \mu \mathrm{g} / \mathrm{ml}$ Bovine Serum Albumin (when required). The reactions were allowed to incubate at the temperature specified by the supplier for three hours. Digested products were separated on a $2 \%$ agarose gel, stained with SybrGold (Molecular Probes Inc., Eugene, OR, USA), and visualized on a transilluminator. Once the utility of these markers was established, the remaining individuals of $T$. dubius, T. miscellus, and T. pratensis were PCR-amplified and digested in the same manner. For nrDNA repeats in T. miscellus, genomic CAPS analysis was conducted as described in Kovarík et al. [65].

For the previously analyzed markers (TDF7, TDF17.4, TDF36.3，TDF44，TDF46，TDF62，TDF72.3，TDF74， TDF85, and TDF90), genomic amplification and restriction digestion were conducted as described in Tate et al. [59]. The Moscow and Pullman populations of T. miscellus were the subject of a previous study [59]; those data are combined here with data for three new loci (cry1, TDF27.10, and nrDNA).

To verify that the observed homoeolog losses based on CAPS analysis were not the result of a point mutation at the diagnostic restriction site in T. miscellus post-polyploid formation, PCR products were sequenced for all individuals of Tragopogon miscellus that showed loss of a homoeologous fragment. For a given individual, a homoeolog loss was scored only when the sequence data verified the pattern from the CAPS gel analysis (i.e., no sequence polymorphisms were detected in the chromatogram either at the diagnostic restriction site or at other positions where $T$. dubius and T. pratensis differ). These same criteria applied for nrDNA loci. However, when the intensity of the digested parental fragments differed in the CAPS gel, the nrDNA patterns were scored as $\mathrm{P}>\mathrm{D}$ or $\mathrm{D}>\mathrm{P}$ to reflect differing copy numbers in the allopolyploid individuals $[65,66]$. For all loci, when a loss was determined, we assumed that both alleles of a parental homoeolog were lost. In cases where one allele of a homoeolog was lost,
CAPS analysis might not detect these losses. Furthermore, identical patterns of loss in individuals from the same population may be the result of shared ancestry. Therefore, total losses from a single population were tabulated as both minimum and maximum number of losses.

\section{Authors' contributions}

JAT designed the study, collected and analyzed genomic CAPS data, and drafted the manuscript. PJ and KAS conducted genomic CAPS analyses. PSS and DES helped to design the study and contributed to drafting the manuscript. All authors read and approved the final manuscript.

\section{Additional material}

\section{Additional file 1}

Summary of homoeolog losses in Tragopogon miscellus. A '+' symbol indicates that no losses were detected in a population for a particular gene. ' $D$ ' or ' $P$ ' following an individual number indicates the parental homoeolog lost ( $D=\mathrm{T}$. dubius; $P=\mathrm{T}$. pratensis) from that individual. Click here for file

[http://www.biomedcentral.com/content/supplementary/14712229-9-80-S1.doc]

\section{Acknowledgements}

This work was supported by a grant from the National Science Foundation (MCB0346437) to DS, PS, and JT and a grant from the Massey University Research Fund to JT. We thank V. Symonds and two anonymous reviewers for comments on the manuscript and the many individuals who have helped with field work, including S. Brunsfield, B. Petersen, and R. Brooks.

\section{References}

I. Soltis DE, Soltis PS, Tate JA: Advances in the study of polyploidy since Plant Speciation. New Phytologist 2003, 161:173-191.

2. Soltis PS, Soltis DE: The role of genetic and genomic attributes in the success of polyploids. Proceedings of the National Academy of Sciences of the USA 2000, 97:705I-7057.

3. Doyle JJ, Flagel LE, Paterson AH, Rapp RA, Soltis DE, Soltis PS, Wendel JF: Evolutionary genetics of genome merger and doubling in plants. Annual Review of Genetics 2008, 42:443-46I.

4. Kellis M, Birren BW, Lander ES: Proof and evolutionary analysis of ancient genome duplication in the yeast Saccharomyces cerevisiae. Nature 2004, 428:617-624.

5. Jaillon O, Aury J-M, Brunet F, Petit J-L, Stange-Thomann N, Mauceli E, Bouneau L, Fischer C, Ozouf-Costaz C, Bernot A, et al:: Genome duplication in the teleost fish Tetraodon nigroviridis reveals the early vertebrate proto-karyotype. Nature 2004, 431:946-957.

6. Wolfe KH, Schields DC: Molecular evidence for an ancient duplication of the entire yeast genome. Nature 1997, 387:708-7।3.

7. McLysaght A, Hokamp K, Wolfe $\mathrm{KH}$ : Extensive genomic duplication during early chordate evolution. Nature Genetics 2002, 31:200-204.

8. Ohno S: Evolution by gene duplication New York: Springer-Verlag; 1970.

9. Furlong RF, Holland PWH: Polyploidy in vertebrate ancestry: Ohno and beyond. Biological Journal of the Linnean Society 2004, 82:425-430

10. de Bodt S, Maere S, Peer Y Van de: Genome duplication and the origin of angiosperms. Trends in Ecology \& Evolution 2005, 20:591-597. 
II. Dehal P, Boore JL: Two rounds of whole genome duplication in the ancestral vertebrate. PLoS Biology 2005, 3:e3I4.

12. Christoffels A, Koh EGL, Chia J-m, Brenner S, Aparicio S, Venkatesh B: Fugu genome analysis provides evidence for a wholegenome duplication early during the evolution of ray-finned fishes. Molecular Biology and Evolution 2004, 2 I: I I46- I I 5 I.

13. Tate JA, Soltis DE, Soltis PS: Polyploidy in plants. In The Evolution of the Genome Edited by: Gregory TR. New York: Elsevier Academic Press; 2005:37I-426.

14. Soltis DE, Albert VA, Leebens-Mack J, Bell CD, Paterson AH, Zhen C, Sankoff D, dePamphilis CW, Wall PK, Soltis PS: Polyploidy and angiosperm diversification. American Journal of Botany 2009, 96:336-348.

15. Vision TJ, Brown DG, Tanksley SD: The origins of genomic duplications in Arabidopsis. Science 2000, 290:2 II4-21 I7.

16. Bowers JE, Chapman BA, Rong J, Paterson AH: Unraveling angiosperm genome evolution by phylogenetic analysis of chromosomal duplication events. Nature 2003, 422:433-438.

17. Kim S, Yoo M-J, Albert VA, Farris JS, Soltis PS, Soltis DE: Phylogeny and diversification of B-function MADS-box genes in angiosperms: evolutionary and functional implications of a 260-million-year-old duplication. American Journal of Botany 2004, 91:2102-21I8

18. Leebens-Mack JH, Wall K, Duarte J, Zheng Z, Oppenheimer D, Depamphilis C: A genomics approach to the study of ancient polyploidy and floral developmental genetics. In Developmental Genetics of the Flower Edited by: Soltis DE, Leebens-Mack J, Soltis PS. San Diego: Elsevier; 2006:527-549.

19. Rauscher JT, Doyle J], Brown AHD: Multiple origins and nrDNA internal transcribed spacer homeologue evolution in the Glycine tomentella (Leguminosae) allopolyploid complex. Genetics 2004, 166:987-998.

20. Valcárcel V, Fiz O, Vargas P: Chloroplast and nuclear evidence for multiple origins of polyploids and diploids of Hedera (Araliaceae) in the Mediterranean basin. Molecular Phylogenetics and Evolution 2003, 27: I-20.

21. Ashton PA, Abbott RJ: Multiple origins and genetic diversity in the newly arisen allopolyploid species, Senecio cambrensis Rosser (Compositae). Heredity 1992, 68:25-32.

22. Brochmann C, Soltis PS, Soltis DE: Multiple origins of the octoploid Scandinavian endemic Draba cacuminum: electrophoretic and morphological evidence. Nordic Journal of Botany 1992, I 2:257-272

23. Cook LM, Soltis PS, Brunsfeld SJ, Soltis DE: Multiple independent formations of Tragopogon tetraploids (Asteraceae): evidence from RAPD markers. Molecular Ecology 1998, 7:1293-1302.

24. Doyle J], Doyle JL, Brown AHD, Palmer RG: Genomes, multiple origins, and lineage recombination in the Glycine tomentella (Leguminosae) polyploid complex: histone H3-D gene sequences. Evolution 2002, 56: $1388-\mid 402$.

25. Wyatt R, Odrzykoski IJ, Stoneburner A, Bass HW, Galau GA: Allopolyploidy in bryophytes: multiple origins of Plagiomnium medium. Proceedings of the National Academy of Sciences of the USA 1988, 85:560I-5604.

26. Segraves KA, Thompson JN, Soltis PS, Soltis DE: Multiple origins of polyploidy and the geographic structure of Heuchera grossuIariifolia. Molecular Ecology 1999, 8:253-262.

27. Soltis DE, Soltis PS: Polyploidy: Recurrent formation and genome evolution. Trends in Ecology \& Evolution 1999, 14:348-352.

28. Werth CR, Guttman SI, Eshbaugh WH: Recurring origins of allopolyploid species in Asplenium. Science 1985, 228:73।-733.

29. Sall T, Jakobsson M, Lind-Hallden C, Hallden C: Chloroplast DNA indicates a single origin of the allotetraploid Arabidopsis suecica. Journal of Evolutionary Biology 2003, 16:1019-1029.

30. Kochert G, Stocker HT, Gimenes M, Galgaro L, Lopes CR, Moore K: RFLP and cytogenetic evidence on the origin and evolution of allotetraploid domesticated peanut, Arachis hypogaea (Leguminosae). American Journal of Botany 1996, 83: I 282-1291.

31. Raybould AF, Gray AJ, Lawrence MJ, Marshall DF: The evolution of Spartina anglica C.E. Hubbard (Gramineae): origin and genetic variability. Biological Journal of the Linnean Society I99|, 43:III- 126

32. Ainouche ML, Baumel A, Salmon A: Spartina anglica C. E. Hubbard: a natural model system for analysing early evolution- ary changes that affect allopolyploid genomes. Biological Journal of the Linnean Society 2004, 82:475-484.

33. Lynch $M$, Conery JS: The evolutionary fate of duplicated genes. Science 2000, 290: II5I-II54.

34. Prince VE, Pickett FB: Splitting pairs: the diverging fates of duplicated genes. Nature Reviews: Genetics 2002, 3:827-837.

35. Barker MS, Kane NC, Matvienko M, Kozik A, Michelmore RW, Knapp $\mathrm{SJ}$, Rieseberg LH: Multiple paleopolyploidizations during the evolution of the Compositae reveal parallel patterns of duplicate gene retention after millions of years. Molecular Biology and Evolution 2008, 25:2445-2455.

36. Paterson AH, Chapman BA, Kissinger JC, Bowers JE, Feltus FA, Estill JC: Many gene and domain families have convergent fates following independent whole-genome duplication events in Arabidopsis, Oryza, Saccharomyces and Tetraodon. Trends in Genetics 2006, 22:597-602.

37. Adams KL, Wendel JF: Exploring the genomic mysteries of polyploidy in cotton. Biological Journal of the Linnean Society 2004, 82:573-581.

38. Levy AA, Feldman M: Genetic and epigenetic reprogramming of the wheat genome upon allopolyploidization. Biological Journal of the Linnean Society 2004, 82:607-613.

39. Wendel JF: Genome evolution in polyploids. Plant Molecular Biology 2000, 42:225-249.

40. Maere S, Bodt SD, Raes J, Casneuf T, Montagu MV, Kuiper M, Peer YVd: Modeling gene and genome duplications in eukaryotes. Proceedings of the National Academy of Sciences of the USA 2005, 1 02:5454-5459.

4I. Bennetzen JL: Patterns in grass genome evolution. Current Opinion in Plant Biology 2007, 10:176-181.

42. Leitch IJ, Bennett MD: Genome downsizing in polyploid plants. Biological Journal of the Linnean Society 2004, 82:65 I-663.

43. Wolfe $\mathrm{KH}$ : Yesterday's polyploidization and mystery of dipIoidization. Nature Reviews: Genetics 200I, 2:333-34I.

44. Ma X-F, Gustafson JP: Genome evolution of allopolyploids: a process of cytological and genetic diploidization. Cytogenetic and Genome Research 2005, 109:236-249.

45. Wang X, Shi X, Hao B, Ge S, Luo J: Duplication and DNA segmental loss in the rice genome: implications for diploidization. New Phytologist 2005, 165:937-946.

46. Gaeta RT, Pires JC, Iniguez-Luy F, Leon E, Osborn TC: Genomic changes in resynthesized Brassica napus and their effect on gene expression and phenotype. Plant Cell 2007, 19:3403-34I7.

47. Kashkush K, Feldman M, Levy AA: Gene loss, silencing and activation in a newly synthesized wheat allotetraploid. Genetics 2002, 160:165I-1659.

48. Lukens LN, Pires JC, Leon EJ, Vogelzang R, Oslach L, Osborn TC: Patterns of sequence loss and cytosine methylation within a population of newly resynthesized Brassica napus allopolyploids. Plant Physiology 2006, 140:336-348.

49. Ozkan H, Levy AA, Feldman M: Allopolyploidy-induced rapid genome evolution in the wheat (Aegilops-Triticum) group. Plant Cell 200I, 13:1735-1747.

50. Udall JA, Quijada PA, Osborn TC: Detection of chromosomal rearrangements derived from homeologous recombination in four mapping populations of Brassica napus L. Genetics 2005 , 169:967-979.

5I. Gaut BS, Doebley JF: DNA sequence evidence for the segmental allotetraploid origin of maize. Proceedings of the National Academy of Sciences of the USA 1997, 94:6809-68I4.

52. Bennett MD, Leitch IJ: Genome size evolution in plants. In The Evolution of the Genome Edited by: Gregory TR. New York: Elsevier Academic Press; 2005:89-162.

53. Ownbey M: Natural hybridization and amphiploidy in the genus Tragopogon. American Journal of Botany 1950, 37:487-499.

54. Brehm BG, Ownbey M: Variation in chromatographic patterns in the Tragopogon dubius-pratensis-porrifolius complex (Compositae). American Journal of Botany 1965, 52:81 I-8I8.

55. Ownbey M, McCollum GD: Cytoplasmic inheritance and reciprocal amphiploidy in Tragopogon. American Journal of Botany 1953, 40:788-796.

56. Soltis DE, Soltis PS: Allopolyploid speciation in Tragopogon: insights from chloroplast DNA. American Journal of Botany 1989, 76:III9-II24.

57. Soltis PS, Plunkett GM, Novak SJ, Soltis DE: Genetic variation in Tragopogon species: additional origins of the allotetraploids 
T. mirus and T. miscellus (Compositae). American Journal of Botany 1995, 82:1329-134|.

58. Novak SJ, Soltis DE, Soltis PS: Ownbey's Tragopogons: $\mathbf{4 0}$ years later. American Journal of Botany |99|, 78: |586-|600.

59. Tate JA, Ni Z, Scheen A-C, Koh J, Gilbert CA, Lefkowitz D, Z Jeffrey Chen, Soltis PS, Soltis DE: Evolution and expression of homeologous loci in Tragopogon miscellus (Asteraceae), a recent and reciprocally formed allopolyploid. Genetics 2006, |73:1599-|6|1.

60. Buggs RJA, Doust AN, Tate JA, Koh J, Soltis K, Feltus FA, Paterson $\mathrm{AH}$, Soltis PS, Soltis DE: Gene loss and silencing in Tragopogon miscellus (Asteraceae): comparison of natural and synthetic allotetraploids. Heredity 2009, 103:73-81.

61. Song K, Lu P, Tang K, Osborn TC: Rapid genome change in synthetic polyploids of Brassica and its implications for polyploid evolution. Proceedings of the National Academy of Sciences of the USA 1995, 92:7719-7723.

62. Tate JA, Symonds VV, Doust AN, Buggs RJA, Mavrodiev EV, Majure LC, Soltis PS, Soltis DE: Synthetic polyploids of Tragopogon miscellus and $T$. mirus (Asteraceae): 60 years after Ownbey's discovery. American Journal of Botany 2009, 96:979-988.

63. McClintock $B$ : The significance of responses of the genome to challenge. Science 1984, 226:792-80I.

64. Shaked H, Kashkush K, Ozkan H, Feldman M, Levy AA: Sequence elimination and cytosine methylation are rapid and reproducible responses of the genome to wide hybridization and allopolyploidy in wheat. Plant Cell 2001, I3:1749-1759.

65. Kovařík A, Pires JC, Leitch AR, Lim KY, Sherwood A, Matyášek R, Rocca J, Soltis DE, Soltis PS: Rapid concerted evolution of nuclear ribosomal DNA in two Tragopogon allopolyploids of recent and recurrent origin. Genetics 2005, 169:931-944.

66. Matyášek R, Tate JA, Lim YK, Šrubařová HS, Koh J, Leitch AR, Soltis $D E$, Soltis PS, Kovařík A: Concerted evolution of rDNA in recently formed Tragopogon allotetraploids is typically associated with an inverse correlation between gene copy number and expression. Genetics 2007, 176:2509-2519.

67. Wendel JF, Schnabel A, Seelanan T: Bidirectional interlocus concerted evolution following allopolyploid speciation in cotton (Gossypium). Proceedings of the National Academy of Sciences of the USA 1995, 92:280-284.

68. Blanc $\mathrm{G}$, Wolfe $\mathrm{KH}$ : Functional divergence of duplicated genes formed by polyploidy during Arabidopsis evolution. The Plant Cell 2004, 16:1679-1691.

69. Lim KY, Soltis DE, Soltis PS, Tate JA, Matyášek R, Šrubařová HS, Kovařík A, Pires JC, Xiong Z, Leitch AR: Rapid chromosome evolution in recently formed polyploids in Tragopogon (Asteraceae). PLoS One 2008, 3:1-13.

70. Soltis DE, Soltis PS, Pires JC, Kovařík A, Tate JA, Mavrodiev EV: Recent and recurrent polyploidy in Tragopogon (Asteraceae): cytogenetic, genomic, and genetic comparisons. Biological Journal of the Linnean Society 2004, 82:485-50 I.

71. Konieczny A, Ausubel FM: A procedure for mapping Arabidopsis mutations using co-dominant ecotype-specific PCR-based markers. The Plant Journal 1993, 4:403-410.

72. Doyle JJ, Doyle JL: A rapid DNA isolation procedure for small quantities of fresh leaf tissue. Phytochemical Bulletin 1987, 19:II-I5.

73. Rozen S, Skaletsky H: Primer3 on the WWW for general users and for biologist programmers. In Bioinformatics methods and protocols: methods in molecular biology Edited by: Krawetz S, Misener S. Totowa, New Jersey: Humana Press; 2000:365-386.

74. Neff MM, Turk E, Kalishman M: Web-based primer design for single nucleotide polymorphism analysis. Trends in Genetics 2002, | $8: 6|3-6| 5$ Publish with BioMed Central and every
scientist can read your work free of charge

"BioMed Central will be the most significant development for disseminating the results of biomedical research in our lifetime. "

Sir Paul Nurse, Cancer Research UK

Your research papers will be:

- available free of charge to the entire biomedical community

- peer reviewed and published immediately upon acceptance

- cited in PubMed and archived on PubMed Central

- yours - you keep the copyright
BioMedcentral 